\title{
BIBLIOGRAFIA
}

HAROLD D. LASSWELL: The selective effect of personality on political participation, in Studies in the scope and method of "The Authoritarian Personality". - Ed. by Richard Christie and Marie Jahoda, The Free Press, Glencoe, Illinois, 1954; págs. 197-225.

Uma das características marcantes da moderna orientação dos estudos de comportamento político é o interêsse por uma colaboração estreita entre cientistas políticos e psicólogos.

Com efeito, quando tratamos de questões de participação politica, isto é, quando procuramos compreender o recrutamento dos adeptos de determinada definição política, entramos num terreno de atitudes, interêsses, símbolos, para cuja compreensão se tornam indispensáveis os métodos e mesmo os modelos teóricos dos psicólogos. Assim, se por exemplo, a análise da emergência e persistência da definição do nacionalismo pode ser feita essencialmente em têrmos da estrutura sócio-econômica e política, prescindindo da referência à pessoa, já o estudo do nacionalista obriga a tal referência e orienta para a compreensão dos motivos que impelem à adoção daquela definição.

Os problemas de participação política costumavam colocar-se, até recentemente, em têrmos do estabelecimento de uma correlação entre a posição ido agente na estrutura sócio-econômica e seu comportamento político. Essa correlação, que revela a influência da posição sócio-econômica na adoção de atitudes, símbolos etc. - fatôres explicativos imediatos do comportamento político - permite, na verdade, atender às necessidades da previsão em grosso. Mas se considerarmos que ocupantes da mesma posição sócio-econômica podem manifestar comportamentos diferentes, enquanto ocupantes de posições sócio-econômicas diferentes podem manifestar o mesmo comportamento - o que é revelado pela própria margem eventual de comportamento discrepante da correlação _- tornase claro que para as próprias necessidades de previsão seria mais vantajoso lidar com os fatôres explicativos imediatos referidos acima. Colocar-se-iam, então, questões da ordem seguinte - a que diferentes motivos correspondem os vários comportamentos políticos? A que alternativas de comportamento pode corresponder um mesmo motivo? E nessa base, procurar-se-ia, com a indispensável colaboração do psicólogo, construir um mapa de distribuição de atitudes, perspectivas, simbolos adotados etc., referentes às divesas respostas que se tratasse de explicar.

No quadro de referências para investigação na Ciência Política apresentado por Lasswell e Kaplan na obra "Power and Society" 1 estão presentes alguns elementos altamente interessantes para a focalização de questões de participação política. Em concordância com o referido esquema, o sujeito da ação, a pessoa, pode ser considerado enquanto membro de um agregado, um nós, com o qual se identifica através do uso de simbolos, traduzindo possivelmente sua auto-representação em respostas

(1) Power and Society - a framework for political inquiry - Lasswell, Harold D.; and Kaplan, Abraham; Londres, 1952, principalmente a primeira parte. 
tendentes a melhorar a posição do agregado com o qual se identifica na constelação de poder. Cada agregado pode representar uma série de reivindicações, expectativas, opiniões. Uma perspectiva seria uma configuração de identificaçōes, reivindicações, expectativas, opiniões. A perspectiva não constitui necessàriamente um todo lògicamente unificado, sendo mesmo possível o conflito entre seus diversos têrmos componentes. Mas de qualquer forma ela representa uma unidade com referência ao agregado, que, por sua vez, pode se compor /de pessoas heterogêneas, polarizadas, entretanto, em tôrno de uma perspectiva.

Dentro de tal esquema, o estudo da constituição dos diversos agregados nos conduz à análise de aspectos referentes à manipulação de símbolos e opiniões, à liderança e organização etc. Dessa forma passam a ser explicados problemas como o da formação eventual, para fins da execução de determinado ato político (eleições, por exemplo), de agregados constituídos às vêzes de pessoas heterogêneas, não só com relação à posição sócio-econômica, como mesmo em relação a identificação, reivindicações ou opiniões. Isso se dá, é claro, na medida em que são manejados, simultâneamente, símbolos e representações dirigidos a êsses elementos heterogêneos e capazes de orientar seu comportamento na direção desejada.

O que foi exposto até aqui nos servirá como ponto de referência para estabelecer as peculiaridades da linha de colaboração entre a psicologia e a ciência política, preconizada por Harold Lasswell no seu trabalho "The selective effect of personality on political participation", com o qual contribui, juntamente com outros cientistas, para a análise dos aspectos mais significativos da obra "The Authoritarian Personality" 2.

Nessa obra, foi estudado exaustivamente um tipo de personalidade que representa uma reação à ansiedade e repressão, através do desenvolvimento de mecanismos obsessivos-compulsivos, aos quais se liga a repetição de modos simplificados de pensamento e expressão. O trabalho representa o resultado dos esforços de uma equipe de psicólogos que refin:aram métodos e técnicas visando o estudo da relação entre personalidade, discriminação social e ideologia política. Esses esforços se situam dentro de uma linha de investigações sôbre a dinâmica do preconceito, investigações das quais Lasswell extrai, como contribuição para a ciência política, um conceito de personalidade centrada no poder ("power centered personality"). A elaboração dêsse conceito se processou através do estudo detalhado das situações de que um individuo participa num determinado período de tempo, com a descrição do grau em que procura impor-se aos outros, através do uso de meios coercitivos.

Na utilização do conceito, recorre Lasswell à noção de "valor" e à tabela de valores por êle já elaborada em outras obras (que inclui o poder ao lado da riqueza, conhecimento etc.) - que passa a empregar, agora, de um ângulo psicológico. Na obra Power and Society, por exemplo, a questão se coloca essencialmente em têrmos da distribuição do valor ou valores entre os membres individuais ou coletivos do grupo considerado. Assim, se consideramos o quadro relativo ao valor poder, constatamos que o próprio esquema referente à pessoa não ultrapassa o nível dos fatôres explicativos imediatos da participação política a que fizemos alusão na primeira parte ídesta resenha, isto é, o plano da possivel influência dos agentes na constelação de poder.

(2) "The Authoritarian Personality" - Adorno, T. W.,; Frenkel-Brunswik E1se; Levinson, D. J.; Sanford, R. N.; in collaboration with Aron Betty; Levinson, Maria H. and Morrow. W. - Harper \& Brothers, Nova York, 1950. 
Na obra que resenhamos, entretanto, altera-se o foco de atenção, que se torna essencialmente psicológico - o problema que se levanta é o da orientação para os diversos valores dentro da estrutura de personalidade. E' dessa ordem a questão da predominância do valor poter na personalidade centrada no poder, explicada por Lasswell como defesa contra a limitação ao acesso aos outros valores. Ou questóes como as seguintes em que medida as frustrações com relação a alguns valores precipitariam o ajustamento da personalidade em têrmos de pader? Em que condicóes o conflito interno é resolvido através do desempenho de um papel ativo ou ,ao contrário, pela fuga, agressão ou suicídio?

De qualquer forma, o problema essencial passa a se localizar no ritmo interno do sistema de personalidade à luz do qual ùnicamente se interpretam as respostas. Naturalmente, na medida em que fôr possivel estabelecer uma correlação entre determinakas respostas, inclusive políticas, e um tipo de personalidade, não apenas o psicólogo poderá fazer preví. sóes de comportamento para um determinado tipo de personalidade, como o cientista político ganhará elementos para a compreensão do comportamento dos agentes. Mas se consideramos que năo só uma personalidade centrada no poder pode exteriorizar seus impulsos destrutivos ou hostis, escolhendo entre diferentes alvos possiveis, como também personalidades do mesmo tipo podem eventualmente orientar-se para definições diferentes, nas quais, entretanto, encontrem satisfações análogas, torna-se claro que o problema da explicação pròpriamente dita passa a colocar-se no nivel dos comportamentos individuais.

Lasswell propõe também algumas questões relativas ao desempenho dos papéis políticos - em que extensão os líderes, na política moblerna, se recrutam entre personalidades centradas no poder ou de outro tipo? A que tipo de personalidade pertencem os detentores de poder efetivo nas diversas comunidades? Quais os tipos de personalidade mais equipados para o exercicio de determinados papéis?

Discutindo as relações entre a psicologia e a ciência politica e preconizando o seu intercâmbio, não nos parece que as importantes contribuições dos psicólogos estudiosos dos problemas da dinâmica do preconceito tivessem sugerido a Lasswell pistas metodológicas mais fecundas para a ciência política do que as já desenvolvidas por êle anteriormente em outros trabalhos. A própria sugestão de aplicação que êle recolhe é nitidamente psicológica, o que provàvelmente resulte antes de uma aceitação de certas premissas daqueles investigadores.

Com efeito, a preocupação com o problema do preconceito, principalmente étnico, levou ao interêsse pelos meios de influir na situação, sem apelar para a transformação estrutural e superando o irreversivel histórico das condições em que o padrão se formou. Passou-se, assim, a encarar essencialmente os agentes, representantes de um determinado tipo de personalidade, caracterizada como não-democrática e tendente ao preconceito. Deslocada do contexto estrutural, a questão passava a colocarse - teòricamente, mas em perspectiva aplicativa - nos seguintes têrmos: atacando-se as condições de frustração, repressão, ansiedade, responsáveis por tal tipo de personalidade, evitar-se-ia a existência de executores para o padrão indesejável e, portanto, eliminar-se-ia o próprio padrão.

As principais contribuições dos psicólogos da "dinâmica do preconceito" para a ciência politica obedecem à mesma orientação; elas visam ao estabelęcimento da relação entre comportamentos políticos considera- 
dos indesejaveis e um tipo de personalidade cuja constituição se deverá evitar.

Mas a discussão dêsse programa de aplicação escapa aos limites lesta resenha.

\section{Paula Beiguelman}

WERner AUlich: O Paraná e os Alemães. Estudo caracterológico sôbre os imigrantes germànicos. Comissão de Festas do Grupo Étnico Germânico do Paraná, Curitiba, 1953, 216 págs., ilustr. Texto em português e alemão.

Publicação comemorativa do $10^{\circ}$ centenário da emancipação política do Estado do Paraná, o trabalho de Werner Aulich tem o fito de apresentar um quadro geral, ainda que necessàriameste resumido, ¿da colonização alemá no Estado vizinho, no que se refere aos seus variados aspectos históricos e sociológicos, desde os seus inicios há mais ou menos 130 anos. Não se limita o autor, portanto, a reunir, de forma seletiva, o material existente sôbre as diversas correntes imigratórias, oriundas de várias partes da Alemanha e de zonas européias de colonização alemã (como, p. ex., os alemães do Rio Volga), historiando a sua atividarle rural e citadina, de colonos, lavradores, tundadores, de descobridores, artesãos, comerciantes, industriais e intelectuais. Apresenta também uma análise sociológica das tensões que surgiram nos processos de integração e mudança cultural, dos problemas de marginalidade, assimilação e aculturação, dos choques entre as "particularidades trazidas" e as "particularidades encontradas", dos antagonismos entre o "anseio pelo novo" e o "apègo ao velho".

A interpretação da transformação do imigrante, de colono, inicialmente forçado a adotar o sistema da agricultura extrativa, em genuíno lavrador e, por vêzes, em idono de grande emprêsa agrícola - para dar apenas um exemplo - elucida a influência de fatôres culturais tipicamente germânicos (particularidades trazidas), ao passo que - para dar outro exemplo - as transformações sofridas pela vida associativa e recreativa, no jôgo entre adaptação íntima e manutenção de formas tradicionais exteriores, mostra muito bem a influência do ambiente físico e cultural brasileiro (particularidaces encontradas).

As categorias da sociologia e la antropologia cultural, manejadas com desenvoltura pelo autor, parecem em si suficientes para explicar os fenômenos descritos. A tentativa de aplicar categorias caracterológicas complica, ao que parece, o esquema do trabalho pelo menos na sua forma atual já que o autor não define exatamente a sua concepção dêsse ramo de psicologia, de significado extremamente vago e multifacetado. Não se nega naturalmente que a interpretação psicológica por exemplo da marginalidade seja de alto interêsse como se vê pela análise da artificialidade e do "disfarce", que ocorrem quando o imigrante procura apresentar "aparências que não têm fundo adequado, quer no intimo das experiências do indivíduo, quer na realidade exterior". Tal análise, entretanto, não requer o recurso a métodos especificamente caracterológicos, ainda em plena fase de elaboração.

O trpbalho de Werner Aulich distingue-se pela objetividade desapaixonada com que o material é apresentado. Evitando o tom apologético, tão freqüente em estudos semelhantes, o autor prestou uma colaboração valiosa ao conhecimento da contribuição alemã para o progresso do Brasil. 